\title{
PROFESSIONELE GEVORMDHEID VAN DIE VERPLEEGKUNDIGE - DIE BEELD VAN DIE BEROEP NA BUITE
}

\author{
Referaat gelewer by die simposium
}

Is ' $n$ beroepsvereniging die antwoord?

\section{PROFESSOR DR WILMA KOTZÉ \\ Departement Verpleegkunde UNIVERSITEIT VAN PRETORIA}

\section{SUMMARY}

\begin{abstract}
The degree of professionalism of a group determines the image which it projects. There are two types of nurses - those who are dedicated to nursing as a career and those for whom nursing is merely a job. The latter group inhibits professional development and the reason for their existence can be sought in two areas - firstly their initial attitude and disposition and secondly the opportunities which were provided for socialisation and professionalisation during their training.

A professional person exhibits specific characteristics and to ensure a high degree of professionalism in nursing it is necessary to:

- select student nurses with care and according to predetermined criteria;

- use all opportunities to build positive attitudes;

- help students to develop an insight into professional affairs and the meaning and demands of professionalism by emphasising these aspects throughout training.
\end{abstract}

'n Persoon is professioneel in die mate dat hy of sy die kenmerke van professionaliteit verwerklik. Professionele erkenning ontspring vanuit die beroep en die beroepspersoon self en nie daarbuite nie. Rosalie C Yeaworth, verpleegopvoedkundige van die Universiteit van Cincinnati, Ohio, identifiseer twee soorte verpleegkundiges -

- diegene wat verpleging bloot as werk beoefen - met ander woorde met die oog op eksterne beloning. Hierdie groep is volgens Norma L Chaska minder geneig tot identifisering met beroepsake en die beroepsvereniging; en

- diegene vir wie verpleging 'n loopbaan is en ingestel is op die intrinsieke bevrediging geleë in rolvervulling. Vir hierdie groep is belegging in die beroep in die vorm van 'n eie persoonlike bydrae tot die georganiseerde beroep van belang (Chaska, 1978, pp. 73 en 408)

Die onderskeid tussen hierdie twee groepe praktisyns lê op die vlak van die persoonlike gesindheid. Indien in ag geneem word dat die aard van persoonlike gesindheid dui op die mate van professionaliteit wat by 'n praktisyn aanwesig is en dat genoemde twee groepe praktisyns, dit is diegene wat verpleging bloot as werk beoefen en diegene wat toegewyde loopbaanbeoefenaars is, aan ons almal bekend is moet ons noodwendig van die veronderstelling uitgaan dat daar in die verpleegberoep 'n aansienlike groep verpleegkundiges is wat die proses van professionalisering, dit is van professionele ontwikkeling, rem. Die betrokkenheid van verleegkundiges die afgelope jaar in pogings aan die een kant, om die beeld van die Suid-Afrikaanse Verpleegstersvereniging in die openbaar af te takel en aan die ander kant, 'n verantwoordelike en opbouend-kritiese benadering van andere tot die Vereniging bevestig die aanwesigheid van ' $n$ verpleegkundige werkers en 'n verpleegkun- dige loopbaan-kategorie in die beroep, ook in Suid-Afrika: 'n kategorie dus met 'n lae en 'n kategorie met 'n hoë profiel van professionaliteit.

Die vraag is nou: waaraan kan hierdie verskynsel toegeskryf word? Ter wille van die openbare beeld van die gehalte van verpleegkundige dienslewering is dit van die grootste belang dat leemtes in die professionalisering van die verpleegkundiges identifiseer en remedieer word. Daar bestaan by die skrywer min twyfel dat die oorsprong van hierdie leemtes geleë is in onvoldoende vorming van die verpleegkundige tot ' $n$ persoon met 'n eie professionele identiteit. Die skrywer wil hiermee te kenne gee dat ten minste 'n deel van die verpleegkundige korps in Suid-Afrika bloot vir verpleegkundige werkverrigting en nie vir verpleegkundige loopbaanvervulling opgelei is nie en, trouens, steeds opgelei word. Onvoldoende professionele ge- 
vormdheid kan, na haar mening, toegeskryf word aan

- ò 'n ontoereikende, negatiewe gesindheid by die persoon self;

- òf gebrekkige vormingsgeleenthede gedurende die opleiding op voor- en naregistrasievlak;

- òf aan beide hierdie faktore.

Die doel van hierdie is nie om die maatstawwe wat voorgehou word vir die oorweging van beroepstatus te stel en ook nie om die kenmerke van die verpleegberoep te meet aan hierdie maatstawwe nie. Wanneer die professionele gevormdheid van die verpleegkundige egter ter sprake kom, is dit aangewese om maatstawwe van dié aard vir riglyne te verken. Indien die kenmerke van 'n beroep soos vertolk in 1973 deur Catherine M Hall van die Royal College of Nursing, Brittanje, oorweeg word as riglyne vir professionaliteit by die verpleegkundige sien die professionele verpleegkundige soos volg daar uit. Sy is naamlik 'n beroepspraktisyn wat in ooreenstemming met die norme van die verpleegberoep:

- in staat is om aan die hand van gespesialiseerde kennis en vaardighede verpleegkundige diens aan die gemeenskap te lewer;

- oor 'n eiesoortige kundigheid beskik wat sy voortdurend ontwikkel en uitbrei om 'n steeds hoër gehalte diens te kan lewer;

- haar verbind tot volgehoue onderrig en ontplooiing van ander praktisyns en studente;

- 'n hoë standaard van dienslewering handhaaf en verbeter;

- haar dienslewering aanpas by veranderende behoeftes;

- verantwoordelikheid aanvaar vir die beveiliging van die persone aan wie sy 'n diens lewer;

- voortgeset poog om die effektiwiteit van die benutting van haar eie kennis, vaardighede en vermoëns en dié van ander praktisyns te bevorder;

- 'n eie bydrae lewer tot die bevordering van die welsyn van verpleegkundige kollegas, studente en ander gesondheidswerkers en hul probleme, wanneer nodig, aan werkgewende owerhede en haar beroepsvereniging vertolk;

- toegewyd is aan dienslewering eerder as aan oorwegings van ekonomiese wins;
- haar verbind tot eerbiediging van die gedragskode gegrond op die etiese beginsels van die verpleegberoep;

- haar volle steun en samewerking gee om die kragte van die verpleegberoep te verenig ten einde sy omvattende doelstellings te bereik;

- haar selfstandigheid as beroepspraktisyn handhaaf as 'n persoonlike bydrae tot die groeiende selfstandigwording van verpleging as beroep binne die raamwerk van die gesondheids- en ander beroepe. (vgl. Smith, 1976, p.33).

In hierdie eise wat Hall vir professionaliteit by die verpleegkundige stel, is daar veel meer geleë as in die tradisionele sieninge van die kenmerke wat 'n professionele persoon behoort te vertoon. Dit is eise vir ware professionele gevormdheid wat na die mening van die referent hier ter sprake is.

Die Nederlandse opvoedkundige, $\mathrm{T} T$ ten Have stel spesifieke vereistes vir gevormdheid by 'n persoon en hy meet die gehalte van gevormdheid aan 'n stel kriteria wat van besondere belang is en aanvullend tot die siening van Hall oorweeg behoort te word. Ten Have se vereistes is drieledig:

- eerstens, die vereiste van integrering: 'n gevormde persoon is iemand by wie alle denke en doen, alle opvattinge en handelinge geïntegreer is tot ' $n$ geheel. Die persoon wat nie 'n geïntegreerde indruk maak nie mag stellig baie weet maar sonder dat hierdie kennis 'n geordende geheel vorm van waaruit hy menings kan vorm en besluite kan neem. Denke en doen by die gemtegreerde persoonlikheid toon verband met mekaar;

- tweedens, die vereiste van identiteit: 'n gevormde persoon is iemand wat konstant in verskillende situasies en op verskillende tydstippe gelykvormig aan homself en voortdurend kenbaar en herkenbaar aan sy denke en handelinge is. Die teendeel hiervan is die persoon wie se mening deur elke ander situasie bepaal en verander word.

lemand die in zijn opinies met alle winde meewait...
(Ten Have, 1970, p.8);

- derdens, die vereiste van selfbestuur: die gevormde persoon se optrede en hele lewe getuig van selfbestuur, selfdissipline en selfordening van waaruit 'n innerlike rangorde van waardes tot stand kom wat sy gedrag en lewe as geheel rig.

Die gehalte van hierdie gevormdheid word volgens Ten Have duidelik uit:

- die gehalte van 'n persoon se waarnemings en kennis, die objektiwiteit daarvan, die afwesigheid van vooroordeel en die mate waarin kennis en ervaring persoonlike besit geword het;

- die gehalte van sy waarderinge en sy voor- en afkeure, sy onderskeidingsvermoë, sy gehoorsaming van die norme, voortdurende selfkritiek met die oog op suiwering en groter innerlike vrywording;

- die gehalte van sy wilsgesteldheid en besluitneming, of dit spreek van verantwoordelikheid en bereidwillige verantwoording, van besonnenheid, oorleg, selfstandigheid, standvastigheid en positiewe gesindheid;

- die gehalte van sy prestasies en skeppinge;

- die gehalte van sy motoriese vaardigheid en die wyse en gesindheid waarmee hy met dinge en materiaal omgaan;

- die gehalte van sy omgang met mense, sy gevoeligheid vir situasies, standvastigheid in verhoudinge, afwesigheid van impulsiewe optrede en die handhawing van 'n eie identiteit in situasies (Ten Have, 1970, pp.712).

Elkeen van hierdie vereistes wat Ten Have aan gevormdheid stel en die maatstawwe wat hy vir die evaluering van gevormdheid voorhou, is van die allergrootste belang en kan met vrug in die evaluering van professionele gevormdheid by die verpleegkundige toegepas word

'n Verdere maatstaf wat by dié van Ten Have vir die evaluering van die gehalte van die professionele gevormdheid van die verpleegkundige, na die mening van die skrywer, gevoeg behoort te word is die van:

- die gehalte van die voorkoms en persoonlike afgerondheid van 
die verpleegkundige. Spreek haar persoonlike voorkoms deur middel van keurige en netjiese kleredrag, haar persoonlike versorging, suiwerheid van taalgebruik, humorsin, stemtoon, liggaamshouding en beweging, die warmte van haar persoonlikheid en haar daaglikse optrede, ook in die openbaar, van 'n geïntegreerde persoonlikheid, 'n eie identiteit en selfgeordendheid. Hierdie maatstaf is uiters belangrik in haar daaglikse voorleef van gevormde verpleegkundigheid aan die jong student, ander lede van die gesondheidspan en die gemeenskap.

In navorsing vir die magistergraad in verpleegkunde in 1974 kom die skrywer tot die gevolgtrekking dat beroepsvoorbereiding en leierskapsvoorbereiding sinoniem is en dat die redes vir gebrekkige leierskap in 'n groot mate in die opleiding geleë is (Kotzé, 1974, p. 154). 'n Opvoedkundige in die Amerikaanse Lugmag, majoor Edward E Jernigan maak in die verband betekenisvolle opmerkings:

Any man worthy of being called a professional must possess those qualities inherent in a good leader and or executive. A leader must have knowledge, skill, self-confidence, and dedication to service; however, just possessing these qualities will not make him a professional. He must possess that enviable desire to put the qualities to use in this advanced technical period. He must constantly strive to increase his knowledge and improve his skills. His dedication to service must serve as an example to his superiors, students, and fellow workers. As he goes to the classroom, the professional can say, I have prepared myself for today's lesson and will be able to communicate with my students and thus they will be challenged to look for further learning situations (Jernigan, 1976, p.213).

Verdere vereistes vir professionele gevormdheid hou derhalwe verband met die kenmerke van effektiewe leierskap, naamlik dat die professioneel-gevormde persoon:

- oor 'n onmiskenbare selfbeskouing, lewensbeskouing en mensbeskouing beskik en ' $n$ fyn balans handhaaf tussen haar loopbaan en private lewe. Die professioneel-gevormde persoon besef die noodsaaklikheid van voortdurende selfondersoek en evaluering ter wille van die ontplooiing van die persoonlikheid en veral van 'n ewewigtige oordeelsvermoë, en haar positiewe gesindheid weerspieël die uitdaging wat elke taak en elke dag vir haar inhou. Haar werkvermoë getuig van fisiese en psigies-geestelike energie en welstand. Die verantwoordelike en suiwere lewenstyl en die ewewig wat sy handhaaf tussen haar kulturele, ontspannings-, tuisen werkaktiwiteite is tiperend van die voorsorg wat sy tref vir die bevordering van haar persoonlike welsyn;

- oor die leierskapsbeskouing en beheer oor situasies beskik wat spreek van haar wete dat die krag van leierskap en van beroepseenheid geleë is in die krag van die gesamentlike poging. As leier besef die professioneel-gevormde persoon die onontbeerlikheid van die identifisering van die positiewe vermoëns van spanlede en/of studente; asook die onontbeerlikheid van ontginning, ontplooiing en uiteindelike samesnoering van hierdie vermoëns tot effektiewe dienslewering en professionele optrede;

- besef hoe noodsaaklik dit is om die student nie net vakkundig voor te berei nie, maar ook vir die volwasse lewe en vir die eise wat professionele loopbaanbeoefening aan haar gaan stel; - bewus is van die kragtige invloed wat sy ter vorming of misvorming van die jong studentverpleegkundige kan uitoefen. Daarom plaas sy haarself, haar onderrigbenadering, haar professionele optrede en uitsprake voortdurend onder die vergrootglas om haar gehalte as vakkundige, lewenspligtige en professionele rolmodel te evalueer en te verbeter. Dit is immers die rolmodel wat die beeld van professionele verpleegkundigheid en van professionele gevormdheid aan die student voorleef. Die rolmodel in hierdie konteks is immers die student se mees kontinue kontak met die leergebeure. Sy beskik oor die unieke geleentheid om aktiewe deel te hê aan nie net die verpleegkundig-vakkundige vorming van die student nie maar ook aan haar vorming as professionele persoon.

Die rolmodel waarna hier verwys word, is die verpleegdosent en veral die saalsuster.

Dit is op dié stadium van pas om met enkele laaste opmerkings oor vorming te volstaan. Faktore wat vormend inwerk sluit alle fasette en invloede in wat in die klaskamer, in die kliniese onderrig, die veld van kliniese praktika en in informele verhoudingsituasies groei- of ontplooiingsmoontlikhede vir die student bied. Hierdie invloede kan onopsetlik, ongerig en toevallig wees, of dit kan doelgerig beplan en georganiseerd voorkom. Geen persoon kan egter deur andere gevorm word nie. Die vorming wat plaasvind kom uit die persoon self. Dit is die resultaat van die verwerking van hierdie invloede deur die persoon of student self. Geen persoon kan gevorm word nie, die geleenthede en moontlikhede vir vorming kán egter en moet derhalwe doelgerig en stelselmatig geskep word. Die gesindheid van die student, haar bereidheid dus om positief of negatief by te dra, tesame met haar aangebore en ontplooide vermoëns, die gehalte van die vormingsomgewing wat vir haar geskep is en haar benutting van die vormingsgeleenthede bepaal uiteindelik die gehalte van gevormdheid (vlg. Oberholzer, 1968, p.85).

Indien die aanvanklike bewering dat die kortsluitings in die ontplooiing tot professionele gevormdheid hoofsaaklik aan een of beide van die faktore ontoereikende/negatiewe gesindheid van die persoon self en onvoldoende vormingsgeleenthede gewyt kan word, in ag geneem word, is dit voor die hand liggend dat dit:

- in die eerste plek baie belangrik is om selektief te wees ten opsigte van aansoeke vir verpleegkundige opleiding. Dit is die oortuiging van die skrywer dat die verpleegstudent, hetsy vir basiese of voortgesette opleiding versigtig en aan die hand van spesifieke kriteria selekteer 
moet word. 'n Onderhoud om enigsins tot 'n persoonlikheidsen daarom ook gesindheidspeiling te kom, word as onontbeerlik beskou. As georganiseerde beroep kan ons nie die negatiewe beeld wat ongevormde professionele persoonlikhede na buite dra bekostig nie. Ons sal die spreekwoordelike armes van gees altyd by ons hê. Daar kan egter doelbewus gepoog word om hul getalle te beperk;

- in die tweede plek belangrik is om die moontlikhede vir die opbou van positiewe gesindhede voortdurend te ondersoek en daar te stel en dit wat verantwoordelik is vir die skep van negatiewe gesindhede te identifiseer en uit te roei. Dit is die oortuiging van die skrywer dat weë vir meer direkte kommunikasie tussen veral die basiese studentgemeenskap en die SuidAfrikaanse Verpleegstersvereniging verken en geskep moet word. Die Vereniging is vir te veel basiese studente ' $n$ vae en teoretiese begrip. Die afdeling Professionele ontwikkeling: opvoedkundig van die Vereniging kan baie doen om hierdie leemte aan te vul. Die daarstelling en verspreiding van onderrighulpmiddels soos skyfie- en klankreekse en 'n film oor die doelstellings, struktuur, kommunikasieweë en werksaamhede van die Vereniging en die inhoude van professionaliteit kan 'n waardevolle bydrae lewer tot die oplossing van hierdie probleem;

- in die derde plek moet die belang van begeleiding van die student tot insig in breëre beroepsaangeleenthede, en die inhoude van en vereistes vir professionaliteit, van die aanvang van opleiding af beklemtoon en integreer word. Die vak Etos van Verpleegkunde behoort vir hierdie doel meer effektief benut te word. Die tyd is waarskynlik ryp vir die ontwikkeling daarvan tot 'n volwaardige kursus wat oor alle studiejare van ten minste die basiese kursusse vir registrasie strek.

Die professionele gevormdheid van die verpleegkundige verbeeld die beroep as diensleweringseenheid na buite. Sy weerkaats ook die beeld van die georganiseerde beroep na buite. Aan haar tekort- kominge en prestasies sal die beroep deur die gemeenskap beoordeel word. Sy is immers verteenwoordigend van die verpleegberoep in die gesondheidsdiensleweringsisteem en in die gemeenskap.

Die vermaning van Earl Nightingale rig ook aan ons 'n uitnodiging tot besinning oor ons eie persoonlike bydrae in beroepsverband.

If we fail as a nation, (profession) it will not come from without, but rather from within. The strength of a nation (the nursing profession) is its people and the degree of their (personal and professional) integrity, (byvoegings van skrywer in hakies) (Earl Nightingale, $8 \mathrm{De}$ sember 1975).

\section{BRONNE:}

1. CHASKA, NORMA L., The nursing profession. McGraw-Hill. New York. 1978. le uitgawe.

2. JERNIGAN, EDWARD Professionalism. Improving College and Universiry Teaching. Volume 24. 1976.

3.KOTZE, W.J., Verantwoordbare leterskap in die verplee gadministrasie. S.A. Verpleegstersvereniging. Pretoria. 1974

4.NIGHTINGALE, EARL Our changing worid. Volume 4 8 Desember 1975.

5.OBERHOLZFR, C.K. Prolegamena van 'n prinsipiele pedogogiek. HAUM. Kaapstad. 1968. 1e uitgawe.

6. SMITH, JAMES P., Sociology and nursing. Churchill L vingstone. Edinburgh/London/New York. 1976. 1e druk.

7. TEN HAVE, T.T., Vorming. Wolters-Noordhoff. Groningen. 1970. 3e druk.

\section{BOOK REVIEW BOEKRESENSIE}

\section{CHANGES IN CARING FOR HEALTH}

\author{
J.C.M. Hattinga Verschure (Ed) \\ H.M. and M. Publishers. Ayresbury. 1980.
}

An international conference was held attended by physicians, nurses, social scientists and handicapped people from various countries, to discuss the current state of and future needs for the provision of health care in industrialised countries. The participants came by invitation; sixteen presented discussion papers and a further twenty-one completed the working party. CHANGES IN CARING FOR HEALTH, edited by J.C.M. Hattinga Verschure, Professor for Hospital Sciences, State University, Utrecht, is a distillation of the contents of the conference papers and the discussions resulting therefrom.

The provision of health care is in a state of change. It is complex and expensive and presents problems in its development which are the concern alike of the professionals who provide it, the communities that finance it and the patients who receive it.

This paperback book strives to show the way ahead and considers the practical implications of innovations in self-care in organised community health services. Changed circumstances of need. public expectations for service, limitations of existing professional resources and economic pressures on the professional sector all contribute to a favourable climate for negotiating a more integrated system of health service using the full social resources in health care. 